\title{
The Undergraduate Feedback Loop: Summarizing, Analyzing, and Acting On Qualitative Student Feedback in Special Collections and Archives Education Programs
}

\section{By Mattherw Strandmark}

\begin{abstract}
This article discusses opportunities for archivists to learn pedagogy skills and the current state of education and instruction programs in special collections libraries and archives. It finds a lack of broad access to pedagogical training in archival graduate programs and continuing education. An alternative approach at the University of Kentucky Special Collections Research Center is presented, including the strategy and impact of soliciting and acting on qualitative student feedback. University of Kentucky's archival assessment program provides a model for analyzing, summarizing, and acting on qualitative undergraduate student feedback to improve the pedagogy of archivists tasked with instruction.
\end{abstract}

\section{Introduction}

Archivists who primarily manage and plan information literacy and primary sourcebased learning sessions and deliver them to undergraduate students too often are tasked with developing a personal pedagogy while balancing the demands of faculty and students. Regularly seen as comprehensive subject experts, these education, instruction, or outreach archivists are also expected to teach lively and creative sessions to students of many different skill levels, in various disciplines of study, and with a range of instructional needs. ${ }^{1}$ Just as often, archivists in these positions have not been formally taught how to teach, or how to use classroom strategies to meet the needs of their students. As instruction and education programs in special collections libraries and archives make great leaps in becoming vital parts of the undergraduate experience, assessments and student feedback that focus on pedagogy are essential to crafting programs that will remain relevant, engaging, and central to the education of undergraduate students.

As formalized information literacy assessment initiatives become more widespread in libraries and archives, archivists may be overwhelmed with vast mountains of data from students with a wide array of backgrounds, experiences, skill levels, and needs. ${ }^{2}$ While information literacy assessment for primary sources is important, the professional literature does not appear to study or examine as frequently the feedback that students provide in response to archival teaching. ${ }^{3}$ This input is even more important as archivists attempt to become well-rounded instructors without a well-established pedagogical training program in the profession. 
The quantitative stress on information literacy assessment programs is important because it provides archivists with data on whether students are learning the right skills during a session. It often falls short, however, in revealing anything about how archivists teach. Students can correctly answer questions about primary source information literacy without gaining much from a learning experience or connecting with the visit's true message. Qualitative student feedback bridges the gap between information literacy assessments and improving the pedagogy of archivists who instruct undergraduate students. Even though undergraduate students may lack a complete understanding of primary source information literacy, their answers and input on what they learn during instruction sessions, the teaching style of the instructor, and possible improvements are the most important feedback available to archivists. If students are unable to connect to the skills being taught, how can we expect them to master and benefit from those skills?

Archivists serving primarily as instructors are often missing the tools and feedback needed to improve their pedagogy and become more skilled teachers. Improving instruction through assessing and analyzing student feedback and creating actionable objectives is central to creating primary source instruction programs that match the goals of faculty and instructors educating undergraduate students. Qualitative student feedback takes great effort to analyze and use to improve teaching, but if archivists can better understand their students' instructional session evaluations, it becomes easier to engage that feedback to improve their pedagogy and better meet student needs. Once feedback is clear and actionable, both instructors and students will benefit.

\section{Literature Review}

The expectation that special collections libraries and archives provide instruction and information literacy sessions to undergraduate and graduate students has become a major concern for many institutions. In an effort spearheaded by the SAA-ACRL/RBMS ${ }^{4}$ Joint Task Force on Primary Source Literacy, new standards have been introduced and accepted by the SAA Standards Committee and now provide a canon for the profession. The sheer number of archival instruction programs necessitated these new guidelines, which differentiate primary source literacy from information literacy standards and programs long in place at institutions of higher education throughout the country. The new guidelines provide a roadmap for meeting the needs of undergraduate students, including, "students' ability to interpret and analyze primary sources and students' ability to apply effective research skills across multiple disciplines." ${ }^{5}$

Primary source literacy and archival instruction are recognized as major trends in the profession. In 2016, Teaching with Primary Sources was included as part of the SAA series Trends in Archives Practice, illustrating the need to fill a "significant gap" in archival literature. The three modules included in the Teaching with Primary Sources volume include a treatment of the theory of archival literacy and primary source literacy, guidance and tips for new instructors, and case studies of example assignments and sessions from archivists in the field. ${ }^{6}$ 
Quantitative studies on the impact of primary source literacy sessions for undergraduate students also show the lasting influence and value of archival instruction in higher education. Morgan Daniel and Elizabeth Yakel's 2013 study published in the Journal of Academic Librarianship reveals that students who experience primary source information literacy sessions and archives orientations benefit from their experiences. ${ }^{7}$

Other survey studies of primary source literacy programs emphasize the widespread coordination between instruction archivists and faculty members, and the frequency with which archivists are asked to step into the realm of pedagogy and instruction. A 2007 study by Doris Malkmus of American history faculty who teach undergraduate students indicates that "teaching with archival sources was complex and demanded considerable time and skill," but is well worth the effort: an average of $71 \%$ of those faculty members indicated that students benefit from archival research. ${ }^{8}$ When faculty members believe that archival instruction is important but find that they do not have the time, knowledge, or flexibility to include it in their courses, they call on archivists to step into the world of instruction in increasingly meaningful and complex ways. Archivists who lead or participate in instruction programs are tasked with coordinating student research with faculty members in wide-ranging disciplines and academic specialties, providing an in-depth orientation to the importance of primary source research, and acting as subject experts for the topics covered in each individual course. The ability of archivists to mold their knowledge of the field to meet the goals of individual courses and faculty members is an increasingly important and valuable attribute in the archival profession.

Quantitative studies and surveys of primary source literacy are already widespread. As also evidenced in the development of the "Primary Source Literacy Guidelines," archivists are skilled at developing and implementing rubrics that provide a clear view of how their instruction provides a quantitative benefit to undergraduate students. ${ }^{9}$ This feedback is obviously helpful and important, but spending the same amount of attention and effort in qualitative assessment would improve the pedagogy of archivists who do instruction or education.

The topics of primary source literacy and archival instruction are already major considerations in the archival field, yet qualitative assessment of student feedback as a tool for improving pedagogy has been relegated to quantitative surveys and specific case studies. The need for an assessment mechanism that harnesses undergraduate student feedback is essential for improving primary source literacy sessions in higher education.

The most recent study to address the need for pedagogical training for future archivists comes from Anderberg et al. Distributed to 53 archival graduate programs throughout the United States and Canada, this study sought to identify whether the graduate programs address the need for archival educators and whether or not they incorporate pedagogical training in their courses. The authors write, "The survey found little pedagogical training in graduate programs for future archivists. . . teaching with primary sources is not a required content area for archives-track students." ${ }^{10}$ 
When purveyors of graduate archival programs were asked whether "your graduate program prepare[s] students to teach with primary sources by offering instruction concentrations, certificates, or other specializations," 67\% of respondents responded "No." Furthermore, when asked if their programs "plan to add any courses, requirements, or certifications in teaching with primary sources in the future," $67 \%$ of respondents indicated "No," and another 11\% responded "Maybe, but no formal plans at this time."11 This study emphasizes a growing area in the archival profession that leading graduate programs in the field are not addressing. Not only is instruction not being taught in archival graduate programs, but very few of the programs surveyed even have plans to develop ways in which archivists can gain a formal, professional, and tactical pedagogical grounding before entering the field.

In the face of expanded instructional roles and lack of formal training in archival graduate programs, archivists have created training programs, conferences, and symposia to address this shortcoming. The Librarians Active Learning Institute-Archives and Special Collections (LALI-ASC) seeks to "develop archivists as teachers by introducing them to the practice of active learning pedagogy." 12 This weeklong training program hosted by Dartmouth College is an effective means for filling the gap left by archival graduate programs and to address the shortfalls inherent in current archival practice related to instruction. While programs like LALI-ASC are beneficial and undoubtedly effective, their reach is limited by archivists' travel or funding constraints. Even if these do not present obstacles for all archivists, each cohort is limited to 12 to 16 archivists per year. ${ }^{13}$

While literature exists in the profession to identify the lack of formal instruction training for archivists, the effectiveness of archival instruction for undergraduate and graduate students, and the utility of quantitative assessment, a gap remains in the literature for archivists who wish to improve their pedagogy and to utilize qualitative feedback to improve their teaching.

\section{Case Study}

This study uses statements from undergraduate students at the University of Kentucky who participated in one or more information literacy instruction sessions taught at the University of Kentucky Special Collections Research Center during the 2017-2018 academic year in a variety of disciplines and at all levels of study (first-year, sophomore, junior, and senior). It examines the responses of undergraduates to three feedback questions asked on the survey:

1. Overall, did you find the class session in Special Collections helpful to the development of your skills as a student/researcher? Please explain your answer.

2. What did you like about the session? What did you learn?

3. In your opinion how could the session be improved? 
This study is meant to show the feedback and assessment process for a college or university special collections library or archives. During the 2017-2018 academic year, the University of Kentucky Special Collections Research Center education program taught and/or led 107 primary source-based learning sessions for undergraduate students, for a total of 2,708 total student visits. These sessions were organized and planned in coordination with University of Kentucky faculty members and instructors. I taught the overwhelming majority of the sessions. This analysis is based on feedback submissions from 271 students. Assessments were distributed electronically via a Qualtrics online survey. Only those students who completed a special collections orientation session were assessed; those in classes who visited for a subject-based activity or tour were not. ${ }^{14}$ The assessment survey was distributed to 658 students, of whom 271 responded, for a survey completion rate of $41 \%$.

The assessed class sessions consisted of a PowerPoint presentation covering the basics of primary source research, using the special collections library, examples of primary source literacy, and historical examples of the importance of primary sources in doing research. Following the presentation, students participated in think-pair-share exercises utilizing a variety of primary source artifacts focused on one historical event, topic, or issue. The same presentation was used for all of the students assessed, and follow-up activities were individualized to the course subject, goals, and instructor needs. In addition to the presentation, students also received a paper handout with instructions on how to use special collections and library databases at the University of Kentucky, how to access collections online, how to request materials for research, and how to analyze primary sources.

\section{Feedback Analysis}

Question 1: Overall, did you find the class session in Special Collections helpful to the development of your skills as a student/researcher? Please explain your answer.

[270 respondents]

As detailed below, the feedback showed that the session taught students about the collections, services, and facilities available (see Appendix A for responses). The most frequent student feedback to this question focused on discovery. Comments revealed that students did not know that the Special Collections Research Center existed, that they had access to the materials highlighted in class, or that they even knew of the existence of archives or special collections libraries in general. Multiple students were glad that they attended the session simply to learn about Special Collections' existence on a large campus with numerous buildings and resources available: "Yes, I did find it helpful. As a freshman it's sometimes hard staying up to date with all the available resources at a school this size. However I answered Yes, somewhat because I have yet to use the special collections resource this year." Some students indicated that they wished the session had shown them more about the building and how to navigate the websites mentioned in the presentation. 
The next recurring feedback for question 1 was that the session served as a refresher for students who had either already visited the Special Collections Research Center for another class, or were already familiar with the topics covered in the presentation. Once again, these students expressed being overwhelmed with the sheer number of resources available on campus, so participating in a session focusing on these resources prepared them well for future research. This feeling was not universal, however. Some students who had already visited for a different class expressed boredom or frustration at having to repeat their visit: "I've gone every semester of college so far so it's just getting repetitive."

Finally, many students expressed their satisfaction with the session because it helped them better understand how to evaluate and use primary sources: "While my research topic was not historically based, it is a tool I can definitely utilize in the future. It also clarified my understanding of a primary and secondary source, as well as giving me tools to evaluate the sources." These comments frequently mentioned how the information could help them with their current classes or projects. They also communicated that, following the session, they felt more comfortable vetting both primary and secondary sources, and deciding which were reliable to integrate into their research projects: "Yes, I didn't even know about the Special Collections Library before we went there as a class. I now know how to get primary sources from there whenever I have a research project. It also helped a lot with learning about primary and secondary sources."

The feedback for question 1 was encouraging, with $94.1 \%$ of students $(255 / 271)$ responding positively and indicating that the session provided value. Only $5.9 \%$ students responded negatively as to whether they found the session helpful in developing their skills as researchers. The majority of student feedback showed that the session was useful, either in introducing new information or in reinforcing procedures and services they had encountered elsewhere. This showed that the presentation content and strategy were successful at least in communicating essential information about how to use the library, how to access collections, and how to utilize primary sources in research.

The students who expressed dissatisfaction also provided valuable feedback about the presentation, though some was difficult to act on. For example, some students thought the presentation was too rushed, while others thought it moved too slowly. Besides these qualms, many students responded that they were still unclear on exactly how to navigate the websites I highlighted at the end of the presentation. This revealed the need to revise the session to leave more time to walk students through how to find and request primary sources online. This also indicated that the handout (see Appendix B) provided to the students was not clear or detailed enough about how to use our databases and websites.

Question 2: What did you like about the session? What did you learn? [263 respondents]

The most common response (approximately 53 students, $20.1 \%$ of respondents) to this question was an outstanding reminder of the main advantage that archivists have 
when working with undergraduate classes: fascinating content. Most of the feedback to this question focused on the materials themselves, both the digital examples in the presentation and the physical resources used in the group exercise. Students expressed their enjoyment of working directly with the primary sources, particularly the tactile, in-person contact with the artifacts and manuscripts. While the skills we focused on were the real point of the class, students were most drawn to and interested in the actual objects. Archivists can use this initial interest as a gateway into teaching or reinforcing valuable research skills.

In their responses to this question, students also expressed satisfaction with how the session helped develop their skills. They mentioned that completing the primary source-based learning exercise improved their skills in public speaking, working in groups, applying historical research to modern issues, working in a fast-paced environment, picking out bias in sources, making connections between their local environment and primary sources, and developing expertise as researchers: "I liked that this session was a smaller class not a huge lecture hall where no one gets involved in terms of participation. I learned how to become a better public speaker something I did not work on in high school"; "I liked that the presenter tried to keep us engaged and inform us of the various types of primary and secondary sources as I did not know the extent of items that fit into those categories." The breadth and frequency of this positive feedback were both gratifying and reassuring as they showed that the class experiences were mostly successful in developing or strengthening a wide variety of skills.

Answering this question, students provided most of the feedback that touched on teaching style and pedagogy. They indicated that the session was successful in engaging their interest, describing it as "interactive, informative, entertaining, enthusiastic, passionate, funny, clear, and upbeat." Perhaps more important, students indicated that the teaching made them feel like I cared about them and their success, and was teaching to help with their development as students and citizens. Students appreciated the changes from their usual class meetings in environment and style, especially noting that the session wasn't "only a lecture," and that "The instructor was nice and very informative. Offered a lot of useful tips to use while researching."

The positive feedback was not universal; some students indicated that they found my teaching boring or repetitive and that they had trouble connecting to the content as a result. This kind of feedback can be disconcerting to instructors, but it is important to realize it contains valuable and useful information. This left me with the feeling that I was on the right track with my teaching style, but that I still had room to improve and to develop my pedagogy in a way that would reach a greater number of students.

Question 3: In your opinion, how could the session be improved? [238 respondents]

The most common suggestion in the feedback for improving the session once again revealed students' deep interest in the materials held in Special Collections. Comments indicated that students wanted to spend more time with the materials and to see a 
greater variety during the session, while reducing the duration of the presentation:

"Less wordy powerpoints, more involvement and activities to keep audience engaged"; "While there wasn't a lot of wasted time the presentation was still rather lengthy and I think it could hold students attention easier if it was shorter." Some students (38; 15.9\%) also indicated that they struggled to understand how to actually incorporate primary or historical sources into their projects. Although these students numbered significantly fewer than those who indicated enhancement of their skills in this area, this still signals room for improvement. Sharing examples of past student research or projects would help students understand effective ways to use primary sources in their own research.

Another major request from students was for help with navigating Special Collections' physical and digital research spaces. Many of the students left the session without a clear understanding of how to actually request materials, visit the library, or navigate our databases: "Maybe incorporate more of the websites into it and give examples of what looks like it is a primary source and actually isn't." These frustrations were similar to those expressed in feedback to question 1.

Finally, question 3's feedback pointed out ways I need to improve my pedagogy. Students who were not completely satisfied with the session wanted my teaching to be more interesting, interactive, exciting, and engaging. Again, feedback varied on the pace of the session. Some students also expressed their concern that too much information was packed into a short amount of time, indicating that I need to ensure that the content I cover in the class sessions matches the amount of time that I have available with students.

\section{Create Action Items}

Based on the feedback from the 2017-2018 academic year, I developed four actionable goals to improve my pedagogy, the quality of our program, and the undergraduate student experience.

1. Incorporate more engaging, interesting, and inspiring stories about the importance of primary sources, and include applicable examples that students can connect to.

This first component deals primarily with changing the content of the presentation. Much of it now focuses on what primary sources are, how to recognize them, what makes them important, and how to analyze them. Based on student feedback, these skills need to be taught through engaging stories, rather than by simply reciting facts. It is also a good reminder to revisit the examples used in class to see if other sources, materials, or artifacts might better make the necessary points. This might include connecting primary sources from our collections to modern news stories with which students might be familiar. For example, the recent removal of Confederate statues in Lexington could be connected to family papers, artifacts, or ephemera related to those historical actors. In addition to sharing more interesting stories, I need to revisit past student projects and connect with faculty members to incorporate real examples of past student work into my presentations. 
2. Create more active learning opportunities to balance out the amount of information included in the learning sessions.

It was almost universally true that students enjoyed the tactile, hands-on experience of working with actual materials more than listening to a presentation. The feedback made it clear that I need to dedicate more time during the sessions for students to work directly with primary sources. Rather than covering information about primary source literacy in the presentation, I need to incorporate skill-building into hands-on learning opportunities. I lost too many students by burying them in information before moving on to what they were really interested in. Perhaps the best remedy would be to change the progression of the class session by breaking up the presentation with a primary source-based activity and then providing additional information on how to locate sources, request materials, and conduct individual research.

3. Make instructions for accessing and navigating the physical and digital Special Collections environments clearer and more detailed.

Even when students enjoyed the session and found it helpful and meaningful, they weren't always clear about how they could later come back and use the resources we worked with in class, or find new ones to use in their research. Because time is always short during the sessions, I included this information at the very end of the presentation, and covered it pretty quickly. I provided each student with a handout detailing how to access digital materials and request physical materials, but this was clearly not adequate. It would be beneficial to spend more time on a concrete example of how to request materials through the online request system rather than simply relying on a handout to act as a surrogate for first-hand experience.

4. Provide examples of how past students used primary sources in their research, and customize each presentation more closely to the goals of each class visit.

Many students found the learning sessions helpful in introducing new concepts, refreshing past experiences, or discovering primary sources with which they connected. Many still struggled, however, in making the next leap and understanding completely how to incorporate primary sources into their research. A couple of examples of successful student projects that I could quickly cover during the presentation might clarify this for students. Similarly, it appears that I need to better customize each visit for undergraduate students. Even when they come only to learn more about primary sources and to build their skill as researchers, I should be able to make concrete connections between discussions in the session and what they are working on in their courses. This might also include closer communication with visiting faculty and instructors to be sure I am on the right track and to better tie in components of the presentation to articles, readings, or videos that students discuss in class. Because syllabi for these courses are already requested and collected from instructors, this should not be difficult.

Even after these changes are made and teaching strategies are adjusted, the idea of the "feedback loop" comes into play. Every academic year, archival educators must identify 
the action items they developed to alter their pedagogy and use the next year's feedback to experiment and try new things. The iterative process is the point; archivists will never be perfect in their teaching, but this process ensures constant improvement and experimentation.

\section{Conclusion}

Instruction archivists who are asked to create meaningful and lasting learning opportunities for undergraduate students must have a clear understanding of how to summarize, analyze, and interpret feedback to have any hope of improving their pedagogy. Paired with quantitative information literacy assessments, qualitative feedback from students is an important part of an assessment program in special collections libraries and archives.

The introduction of the "Guidelines for Primary Source Literacy" by the joint SAA/ ACRL-RBMS task force marks the culmination of years of diligence and striving in the field to establish the significance of archival and special collections instruction programs throughout the country. While research and assessment of general student experiences in the archives and coordination between faculty members and archivists have been studied at length, far less attention has been paid to harnessing qualitative student feedback to improve the pedagogy of archival educators.

Likewise, graduate school is not teaching future archivists how to instruct. Current archivists are not provided with adequate or widespread opportunities to develop their pedagogy. Archivists responsible for instruction work mostly with what they have: the qualitative feedback from the students they serve on a day-to-day basis. While more difficult to both quantify and to act on, this "soft" feedback is essential for archivists to improve their pedagogy.

This case study, and the overall assessment environment of primary source instruction in higher education, encourages archivists who can translate what students say to make constant changes to their instruction programs. The process outlined in this study should serve as a roadmap for other instruction archivists to use the valuable feedback received from their students to create a "feedback loop" for use in their instruction programs. Heeding student feedback will continue to be essential in improving primary source literacy and special collections/archives education programs in the changing landscape of postsecondary education. 


\section{ABOUT THE AUTHOR}

Matthew Strandmark is the education archivist and academic liaison for Appalachian Studies at the University of Kentucky Special Collections Research Center, where he works closely with faculty and instructors to design, deliver, and assess active learning sessions to undergraduate and graduate students. Previously, he served as outreach archivist at Emory University's Stuart A. Rose Manuscript, Archives, and Rare Book Library. Strandmark received his MLS and MA (history) from Indiana University, Bloomington, and a BA in history and political science from Hanover College in Hanover, Indiana.

\section{NOTES}

1. "Guidelines for Primary Source Literacy," Society of American Archivists, https://www2.archivists .org/standards/guidelines-for-primary-source-literacy.

2. Magia G. Krause, "Undergraduates in the Archives: Using an Assessment Rubric to Measure Learning," American Archivist 73, no. 2 (2010): 521.

3. Matthew Strandmark, original research, 2018.

4. Society of American Archivists, Association of College and Research Libraries/Rare Books and Manuscripts Section.

5. "SAA-ACRL/RBMS Joint Task Force on Primary Source Literacy," Society of American Archivists, https://www2.archivists.org/groups/saa-acrlrbms-joint-task-force-on-primary-source-literacy.

6. Christopher J. Prom and Lisa Janicke Hinchliffe, eds., Teaching with Primary Sources, Trends in Archival Practice series (Chicago: Society of American Archivists, 2016).

7. Morgan Daniels and Elizabeth Yakel, "Uncovering Impact: The Influence of Archives on Student Learning," The Journal of Academic Librarianship 39 (June 2013): 414.

8. Doris J. Malkmus, "Teaching History to Undergraduates with Primary Sources: Survey of Current Practices," Archival Issues 31, no. 1 (2007): 25.

9. Krause, "Undergraduates in the Archives, 507.

10. Lindsay Anderberg et al., "Teaching the Teacher: Primary Source Instruction in American and Canadian Archives Graduate Programs," American Archivist 81, no. 1 (2018): 188.

11. Anderberg et al., "Teaching the Teacher," 197.

12. "Librarians Active Learning Institute-LALI," Dartmouth Library, https://www.dartmouth .edu/ library/home/about/lali/.

13. "Librarians Active Learning Institute-LALI."

14. University of Kentucky Special Collections Research Center, 2017-2018 Instruction Assessment Data, bit.ly/UKYfeedback.

15. "Guidelines for Primary Source Literacy."

16. Daniels and Yakel, "Uncovering Impact"; Malkmus, "Teaching History to Undergraduates with Primary Sources." 


\section{APPENDIX A: STUDENT SURVEY}

1. Indicate your Professor/Instructor: (Drop-down menu)

2. Indicate your course title/number: (Drop-down menu)

3. List the websites or methods you would use to LOCATE resources at the University of Kentucky Special Collections Research Center.

4. Which of the websites or methods you listed was most helpful for YOUR research/ assignment? Please describe why.

5. What is a Collection Guide or Finding Aid and how does it help you NARROW your research and IDENTIFY relevant information?

6. What is the DIFFERENCE between a primary source and a secondary source?

7. List 3 different TYPES of primary sources.

8. Describe 3 types of EVALUATIVE CRITERIA you would look for to determine if a primary source or document was relevant or useful to your topic, class project, or research.

9. Overall, did you find the class session in Special Collections helpful?

10. Please explain your answer-why Yes or No?

11. What did you like about the session? What did you learn?

12. In your opinion, how could the session be improved?

13. Please choose your classification. (Options of first-year, sophomore, junior, senior, other) 


\section{APPENDIX B}

\section{He Libraries}

\section{Special Collections Research Center \\ Research Tools and Resources}

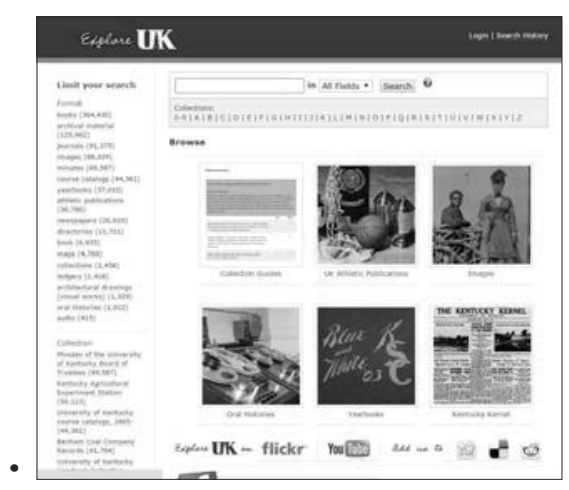

\section{ExploreUK}

http://exploreuk.uky.edu

- Digitized Primary Sources

- Historical Photos and Images of UK and across KY

- UK Yearbooks, Newspapers, Sports Publications

- Oral History Interviews - Listen or Watch

- Available 24/7

- Limit your search to "Collections" to view Collections Guides and Finding Aids for Research Collections

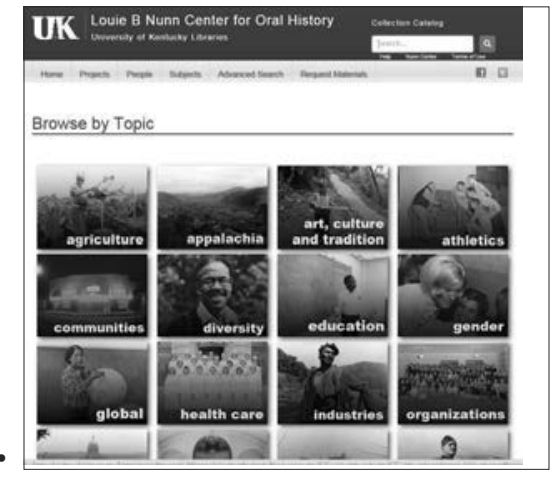

Louie B. Nunn Center for Oral History http://www.kentuckyoralhistory.org

- Listen to Oral History interviews

- Watch Video interviews

- Search the SPOKEdb catalog for additional audio collections 

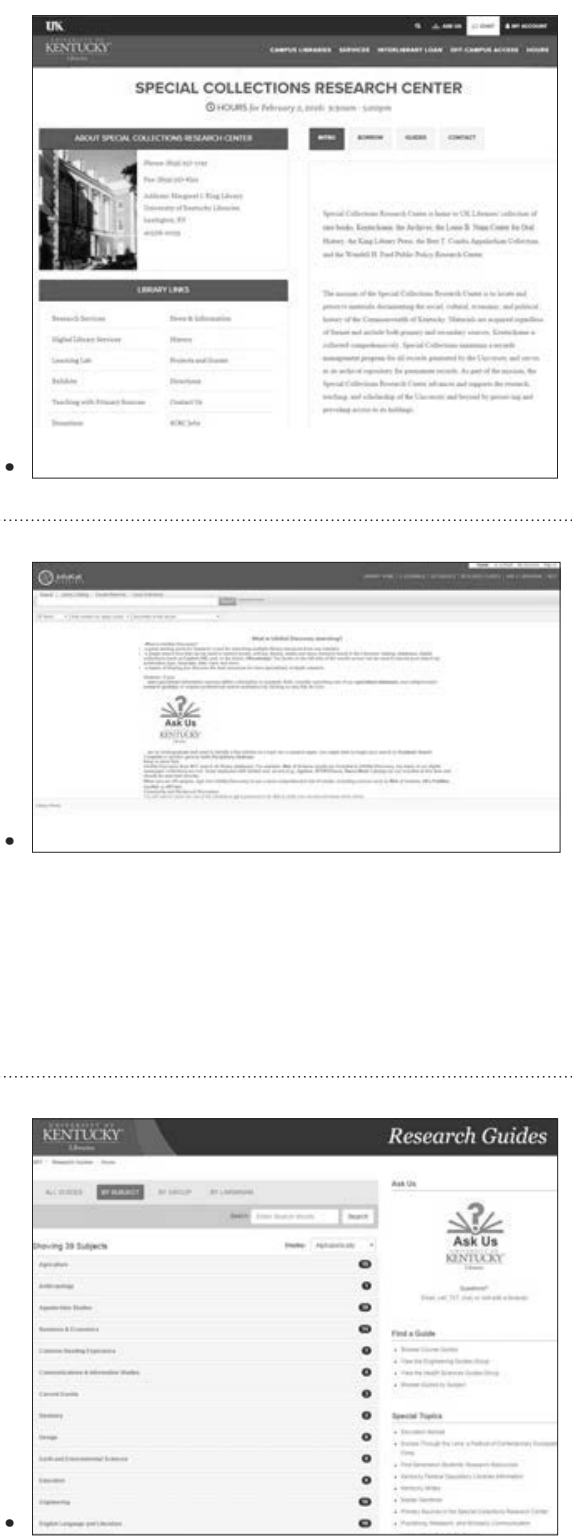

\section{Special Collections Website} http://libraries.uky.edu/SC

- Review research Policies and Procedures

- Find Contact Information

- Read about our Services and Programs

- Find Primary Source Research Guides for many topics

\section{UK Libraries' Catalog, InfoKat Discovery http://infokat.uky.edu}

- Search for books, research collections, and more

- Use the Advanced Search to maximize your options

- Limit your search to "Location: Special Collections" or combine other search criteria to narrow results

\section{Primary Source Guides} http://libguides.uky.edu/index. php?gid $=1340$

- Browse our Collections by Subject Area

- Explore potential research topics and see how much is available on a particular subject 


\section{㯊 Libraries}

\section{Special Collections Research Center}

\section{Register/Request Materials}

\section{Follow these steps if you need to research materials in-person:}

1. Register as a user at requests-libraries.uky.edu. Log in using your Link Blue account and complete registration.

2. Visit exploreuk.uky.edu to search for collections. Expand a collection and click the "Request" button. When you select the boxes you want to use, select which date you plan to visit, and submit your requests.

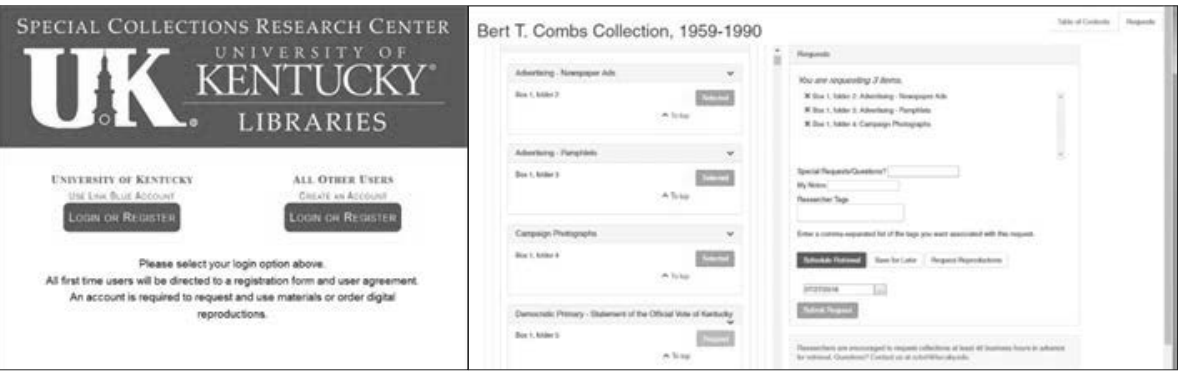

3. Visit the Research Room in the SCRC to see the materials.

\section{Evaluating Primary Sources}

While doing research with any primary source, ask yourself these questions:

- Is the source authoritative?

- Is the source contemporary?

- Does the source have relevance to my topic?

- What was the purpose of the source, and does it show any bias?

- In what context was the source created?

- How accurate is the source, and what quality of information does it provide? 